\title{
Atualidades de Schopenhauer: Direitos Humanos de Terceira Geração*
}

\author{
The actuality of Schopenhauer's Philosophy: The Human Rights of \\ Third Generation
}

Felipe Durante

xfelipedurantex@gmail.com

(Universidade Federal do Acre, Acre, Brasil)

\begin{abstract}
Resumo: Este artigo tem por objetivo, a partir da leitura e análise de textos éditos e do espólio filosófico de Arthur Schopenhauer, em especial aqueles referentes à ética do autor, apresentar possibilidades de leituras sobre a atualidade do filósofo da vontade no que se refere aos Direitos Humanos de terceira geração, em especial o direito a um meio ambiente preservado.
\end{abstract}

Palavras-chave: Arthur Schopenhauer; ética; atualidade; Direitos Humanos de terceira geração; direitos ambientais.

\begin{abstract}
This article aims to show possibilities of readings about the actuality of Schopenhauer's work with regard to the third generation of Human Rights, especially the right to a preserved environment. It was based on the critical reading of the published and unpublished texts by the philosopher Arthur Schopenhauer (1788-1860), in particular his texts about Ethics.
\end{abstract}

Keywords: Arthur Schopenhauer; Ethics; Actuality of Schopenhauer's Philosophy; Third Generation Human Rights; Environmental Rights.

DOI: http://dx.doi.org/10.11606/issn.2318-9800.v25i4p31-40

\section{Direitos Humanos e Direitos Humanos de Terceira Geração}

Quando se escreve sobre a possível atualidade de um filósofo, acaba-se por fazer um exercício de reflexão e interpretação de sua filosofia e da atual conjuntura local, regional, setorial, ou mundial, dependendo do aspecto a ser analisado e trabalhado. Os resultados apresentados, algumas vezes, podem ser entendidos mais como uma provocação e um convite à reflexão do que como uma questão esmiuçada e já resolvida. São esses os horizontes desse texto: o da provocação e o do convite à reflexão.

As primeiras questões que poderiam ser apresentadas sobre os objetivos aqui propostos poderiam ser: o que seriam os Direitos Humanos de terceira geração e

* Este artigo é fruto da atualização e reescrita de uma seção da tese de doutoramento do autor, intitulada Direito natural e direitos fundamentais: a atualidade de Schopenhauer para o debate acerca dos direitos humanos (Durante, 2017). 
como seria possível relacioná-los à filosofia de Schopenhauer, i.e., a filosofia de Schopenhauer se ocupa, direta ou indiretamente, dessa temática? O que uma filosofia estigmatizada de forma simplista como pessimista poderia contribuir para um debate sobre Direitos Humanos?

Por questões metodológicas e de fluidez no encadeamento dos argumentos que pretendo apresentar, é adequado iniciar essa exposição explicando o sentido pelo qual a expressão Direitos Humanos de terceira geração é empregada nesse texto. 0 termo Direitos Humanos de terceira geração foi cunhado pelo jurista tcheco-francês Karel Vašák, então diretor da Divisão de Direitos do Homem e da Paz da UNESCO, em sua aula inaugural intitulada Pour les Droits de l'Homme et la Troisième Génération: Les Droits de Solidarité aos cursos do Instituto Internacional dos Direitos do Homem, em Estrasburgo no dia 2 de julho de 1979 (cf. Bonavides, 2006, p. 563).

Segundo história reproduzida em diversos livros e artigos em língua portuguesa (cf. Marchi, 2010), ${ }^{1}$ Vašák confessou ao jurista brasileiro Antonio Augusto Cançado Trindade que à época daquela conferência ele não dispunha de tempo suficiente para preparar uma exposição minuciosa e prestou-se a fazer uma reflexão na qual associava à bandeira de França e ao lema "Liberdade, Igualdade, e Fraternidade" o que ele chamou por gerações do direito: a primeira geração como direitos de liberdade, a segunda geração como direitos de igualdade, e a terceira geração como direitos de fraternidade.

Um dos teóricos da filosofia do direito mais importantes do século $X X, 0$ jusfilósofo italiano Norberto Bobbio, toma de empréstimo a nomenclatura cunhada por Vašák, e a incorpora como ferramenta hermenêutica em sua obra A Era dos Direitos (L'Età dei Diritti). ${ }^{2}$ Essa obra marcou as discussões sobre filosofia do direito, tornando-se um clássico até hoje utilizado como guia ou contraposição para o debate acerca dos Direitos Humanos e da história dos direitos recentes.

10 artigo faz a seguinte transcrição do discurso proferido por Cançado Andrade na Câmara dos Deputados de Brasília: "Em primeiro lugar, essa tese das gerações de direitos não tem nenhum fundamento jurídico, nem na realidade. Essa teoria é fragmentadora, atomista e toma os direitos de maneira absolutamente dividida, o que não corresponde à realidade. Eu conversei com Karel Vasak e perguntei: 'Por que você formulou essa tese em 1979?'. Ele respondeu: 'Ah, eu não tinha tempo de preparar uma exposição, então me ocorreu fazer alguma reflexão, e eu me lembrei da bandeira francesa'. Ele nasceu na velha Tchecoslováquia. Ele mesmo não levou essa tese muita a sério, mas, como tudo que é palavra 'chavão', pegou. Aí Norberto Bobbio começou a construir gerações de direitos etc.".

2 Existe atualmente um grande debate acerca da nomenclatura mais acertada para designar tais tipos de direito: gerações, dimensões, categorias, espécies, naipes, ondas. Também se discute sobre a existência de outras gerações dos direitos humanos. Alguns autores discorrem sobre a quarta geração de direitos humanos, mas sem alcançar exatamente um consenso sobre o seu conteúdo. Por outro lado, no que parece ser uma hiperinflação da terminologia, alguns autores chegam a reivindicar a existência de direitos de quinta, sexta, sétima, oitava e até nona geração / dimensão. Optamos aqui pela utilização do termo geração, unicamente para manter a uniformidade com o termo empregado por Bobbio, autor que auxilia e embasa nossa argumentação. Uma introdução sobre o debate referente à melhor terminologia a ser empregada pode ser encontrada em Marchi (2010). 
Para Bobbio, uma análise atenta da história mostra que os direitos não são dados por governantes aos governados, mas conquistados através da reivindicação e do embate:

a liberdade religiosa foi o resultado das guerras de religião, as liberdades civis, resultado das lutas dos parlamentos contra os soberanos absolutos, a liberdade política e as liberdade sociais foram resultados do nascimento, crescimento e amadurecimento do movimento dos trabalhadores assalariados, dos camponeses com pouca ou nenhuma terra, dos pobres que demandam ao poder público não apenas o reconhecimento da liberdade pessoal e da liberdade negativa, mas também a proteção do trabalho contra o desemprego, as primeiras demandas rudimentares contra o analfabetismo, e também a assistência por invalidez e idade, tudo aquilo que os proprietários abastados podiam prover por si mesmos (Bobbio, 1995, pp. XIII-XIV).

Além disso, os direitos não nascem e morrem - ou são conquistados e perdidos - todos de uma única vez, mas apenas quando podem ou devem nascer ou morrer (Bobbio, 1995, p. XV). Certas demandas nascem somente quando nascem certas necessidades; e as necessidades nascem das mudanças das condições sociais, e quando desenvolvimentos tecnológicos permitem satisfazê-las (idem, p. XVI). Dessa forma, o contexto histórico-social deve reunir as condições de possibilidade para que os direitos surjam como pontos norteadores ideais, ou já como efetividades.

Alguns eventos históricos possuíram e criaram atmosferas fecundas para o surgimento e a positivação de direitos. Podemos citar, dentre tantas possibilidades observadas ao longo de nossa história, alguns deles, como A Lei de Habeas Corpus, na Inglaterra em 1679; A Declaração de Direitos (Bill of Rights), também na Inglaterra, em 1689; A Declaração de Independência e a Constituição dos Estados Unidos da América do Norte de 1776; e, obviamente, a Declaração de Direitos do Homem e do Cidadão de 1789, fruto da Revolução Francesa.

Dessa forma, nessa lógica de conceber a origem dos direitos, eles foram classificados posteriormente por Bobbio da seguinte forma: como (i) direitos tradicionais, os quais lidam exclusivamente com as liberdades individuais e políticas, mas apenas no sentido negativo, i.e., a liberdade entendida como ausência de coação, como o não atuar do Estado, como a não ingerência do poder público regulador das interações sociais na vida cotidiana dos indivíduos. Trata-se, aqui, basicamente do asseguramento de direitos cuja titularidade corresponde unicamente ao indivíduo, aos seus direitos civis, como, por exemplo, as liberdades religiosas, de expressão, e de imprensa. Como (ii) direitos sociais (de igualdade), os quais lidam com aquilo que os indivíduos podem ou devem ter acesso, como saúde, educação, cultura, emprego, habitação; para que esses direitos possam ser garantidos é necessária a intervenção e a atuação do Estado. E como (iii) direitos difusos ou coletivos (de fraternidade, também conhecidos por “direitos de solidariedade"), os quais, a partir do século XX, segundo Bobbio, surgiram como a terceira geração de direitos, que, embora ainda 
constituíssem uma categoria muito heterogênea e vaga para que fossem definidos de forma precisa, abrangeriam a preservação do meio ambiente, numa clara preocupação com a manutenção da vida na Terra. ${ }^{3}$ Isso significa que os titulares de direitos de terceira geração não seriam mais indivíduos, mas uma certa coletividade social que se outorgaria o direito de preservação e se obrigaria a cumpri-lo, uma vez que todo direito outorgado deve necessariamente acarretar uma obrigação.

É bem verdade que muitos desses direitos não foram positivados e não possuem ainda instrumentos assecuratórios próprios, mas isso não significa que não se possa afirmar que tais direitos deixem de ser sentidos no meio social como exigências impostergáveis (Comparato, 2015, p. 152), e, dessa forma, possam ser reivindicados.

Dadas as linhas gerais e básicas sobre os direitos humanos e suas gerações, pode-se dizer genericamente que, enquanto os direitos de primeira geração colocam limites ao Estado, os direitos de segunda geração estabelecem as diretrizes para o agir do Estado no tocante ao asseguramento do mínimo de condições necessárias no que concerniria uma vida digna; e que os direitos de terceira geração - os direitos de fraternidade e solidariedade - podem ser entendidos, basicamente, como a aspiração coletiva de preservação e de conservação do meio ambiente, e, assim, eles apontam para um horizonte de como os Estados e as sociedades devem se empenhar na preservação do meio ambiente para a manutenção da vida e de condições adequadas para as futuras gerações.

Explicitado o sentido pelo qual nos referimos aos Direitos Humanos de terceira geração, é possível pensar em quais aspectos é lícito criar relações entre eles e a filosofia de Arthur Schopenhauer.

\section{Estratégias de Autoconservação: Egoísmo(s) e Compaixão}

Como bem sabido por aqueles que são familiarizados com a filosofia schopenhaueriana, a vontade (Wille) é um impulso cego e irracional, que tem no desejo a expressão de sua estrutura de movimento pela busca de um objeto de satisfação, uma estrutura que a condena a sempre repetir tal movimento de forma necessária. Esse querer revela um interesse pela própria preservação e manutenção da vida, nas melhores condições possíveis. São várias as estratégias da vontade em se autoconservar e em se afirmar. A obra Sobre a Vontade na Natureza (Über den Willen in der Natur), por exemplo, pode ser entendida como uma tentativa de Schopenhauer catalogar várias dessas estratégias da vontade que aparecem na complexidade de relações da biosfera terrestre; tudo isso com a finalidade de comprovar empiricamente a sua filosofia da vontade. Mas é no ser humano, o grau

3 Bobbio se refere aos direitos de terceira geração da seguinte forma: "o mais importante deles [direitos abrangidos pela terceira geração de direitos] é o reivindicado pelos movimentos ecológicos, o direito a viver em meio ambiente não poluído" (Bobbio, 1995, p. XIV-XV). 
de objetivação mais alto que a vontade atinge, onde ela encontra a possibilidade de manifestar-se e afirmar-se de modo pleno.

No ser humano é possível notar a vontade procurando meios para conservarse, para continuar sendo, nas melhores condições possíveis, seja no mais basilar egoísmo (Egoismus), que procura apenas a autossatisfação e a autoconservação, seja no egoísmo esclarecido. Através deste, com o uso da reta razão (Recta Ratio), o Estado é concebido como forma de regular as relações sociais e, assim, assegurar uma gama mínima de direitos e proteções.

Dessa forma, o egoísmo aparece em sua perspectiva prática como sinônimo da afirmação da vontade para vida e como uma consequência da busca pela autopreservação e autossatisfação, sendo, assim, uma condição natural do ser humano. Ele apresenta a característica dual de ser, ao mesmo tempo, o fator que engendra conflitos - quando os indivíduos concorrem pelos mesmos fins ou possuem meios conflitantes (egoísmo basilar) -, e o fator que resolve conflitos - quando a resolução apresentada se mostra mais vantajosa que o conflito (o egoísmo esclarecido).

Outra estratégia da vontade em se autoconservar poderia ser a compaixão (Mitleid). A compaixão é uma das motivações fundamentais para o agir humano (Cf. Schopenhauer, 2001, p. 137; Schopenhauer, 1911-1942, pp. 680-681), na qual o bemestar alheio e a diminuição do sofrimento do outro se tornam o motivo do agente. Seria um tipo diferente da conservação egoísta, em seu aspecto prático e em sua raiz metafísica: no cuidado e na conservação desinteressados do outro abre-se a possibilidade de pensar, não mais por bases egoístas, o cuidado e a conservação coletiva; e no cuidar e conservar de forma desinteressada o outro, acaba-se, muitas vezes, por conservar e cuidar de si mesmo, porque, no sistema filosófico schopenhaueriano, compartilhamos a mesma essência metafísica.

Para criar um Estado que cumpra da melhor forma sua finalidade, a proteção da existência de cada indivíduo, primeiro seria necessário criar seres cuja natureza permita a eles sempre sacrificarem o próprio bem-estar em favor do bem-estar público. Ou seja, estes seres devem ser capazes de abdicar de uma forma elementar da própria afirmação da vontade para vida - devem abdicar de seu egoísmo - em prol do bem-estar coletivo. Trata-se do indivíduo ético, justo, caritativo; aquele que preza a afirmação do outro e dá a cada um o que é seu, não lesando ninguém.

Mas Schopenhauer classifica essa possibilidade como uma espécie de utopia. Para além de utopia, parece-nos uma contradição com sua doutrina do caráter, na medida em que seria o resultado de um programa racional, de uma deliberação da razão que, de algum modo, atuaria como instância superior de orientação dos rumos da vontade metafísica. Entretanto, a condição usual, o impulso motivacional recorrente e predominante é o egoísmo. Como seria possível pensar a preservação global de nosso meio ambiente e da vida planetária quando isso significa frear impulsos egoístas 
de consumo e de satisfação, ao mesmo tempo em que o esgotamento dos recursos naturais e a ameaça da nossa existência ainda parecem uma distante possibilidade?

\section{Possibilidades de Desdobramentos da Questão}

Apesar do constante alerta de organizaçõos internacionais de proteção ao meio ambiente, como a World Wide Fund for Nature (WWF) ${ }^{4}$ e a Global Footprint Network $(G F N)^{5}$, de que os recursos naturais de nosso planeta estão sendo utilizados de forma predatória e insustentável, e de que essa forma de exploração produz alterações na dinâmica de funcionamento e equilíbrio de toda a biomassa de nosso planeta, pouco tem sido feito de forma que se altere efetivamente a configuração estabelecida dos modos de exploração do meio ambiente. ${ }^{6}$

A questão financeira e mercadológica, no mais das vezes, possui preponderância sobre a preservação ou o uso sustentável de recursos naturais. Tem-se, assim, uma atmosfera desfavorável à efetivação dos Direitos Humanos de terceira geração. A partir da filosofia schopenhaueriana, alguns cenários podem ser vislumbrados no que concerne à questão desses direitos. Poder-se-ia pensar a questão, ao menos, a partir de duas perspectivas: (i) a partir da perspectiva do papel e da finalidade do Estado; e (ii) a partir da perspectiva das motivações que fazem com que os indivíduos ajam.

No segundo volume de sua obra mais importante, mais precisamente no capítulo 47, Schopenhauer escreve sobre as funções do Estado. 0 Estado surge como o regulador das relações humanas, possuindo, segundo o autor, a finalidade de proteger e resguardar: a proteção contra ameaças externas (Schutz nach Außen), a proteção contra ameaças internas (Schutz nach Innen), e a proteção contra o protetor (Schutz gegen den Beschützer), i.e., o direito à resistência.

Schopenhauer é muito claro ao definir o que significa garantir a proteção interna e externa dos cidadãos de um Estado. Significa impedir que as relações de injustiça reinem no âmbito interno de um Estado, e, no âmbito externo, proteger seus integrantes de ataques advindos de outros Estados. Trata-se de uma proteção que se configura de forma negativa, vigilante, e repressora, que garante a integridade física e a propriedade dos indivíduos. É, nesse sentido, um esforço coletivo em conservar

4 A WWF produz e publica a cada dois anos um relatório sobre a situação da biodiversidade, dos ecossistemas, e as demandas sobre recursos naturais. Os dois últimos relatórios da WWF apontam para um colapso ambiental (2016 e 2018).

5 É possível acessar os relatórios da entidade que alertam para o uso desmedido de recursos naturais (GLOBAL FOOTPRINT NETWORK, s.d.). Em maio de 2020 foi publicado um estudo quantitativo na Revista Scientific Reports - Nature (Bologna \& Aquino, p. 2020) que alerta para os riscos de um colapso ambiental irreversível em questão de décadas.

6 Como exemplo de resistência a medidas que visam proteger o meio ambiente, é possível lembrar da recusa dos Estados Unidos em ratificar o Protocolo de Quioto sob a alegação de que isso prejudicaria a economia do país; outros países ratificaram o Protocolo, mas não conseguiram cumprir as metas estipuladas. 
a vida de cada um dos cidadãos no seio da sociedade.

Como apontamos, a questão dos Direitos Humanos de terceira geração é uma questão que ganhou forma e contornos mais delineados apenas recentemente. Tratase de uma nova demanda, nascida de uma nova necessidade, fruto de mudanças das condições e relações sociais ao longo dos últimos séculos. Nesse ponto, se nos fosse lícito questionar em que medida a garantia de conservação do meio ambiente em que o indivíduo está inserido não pode estar dissociada da garantia de conservação do próprio indivíduo, seria possível atualizar e, por assim dizer, alargar o conceito schopenhaueriano de proteção, caracterizando a proteção interna, também, como a garantia de um meio ambiente saudável para que o indivíduo possa viver. Se admitimos esse alargamento conceitual, teríamos uma ligação estrita entre o direito à vida e o direito a um meio ambiente preservado. E o Estado teria de aplicar seus esforços em garantir ambos. Parte desses esforços residiria no fato de que o Estado teria de consentir que crimes ambientais configuram um tipo de injustiça, ${ }^{7}$ adicionando ao código penal (cf. Schopenhauer, 2005, p. 391; Schopenhauer, 1911-1942, p. 407), ${ }^{8} \mathrm{o}$ índice de contramotivos às ações criminais, um contramotivo mais forte aos eventuais motivos de não preservar o meio ambiente.

Ainda sob a perspectiva da finalidade do Estado, podemos elaborar o seguinte raciocínio: o ser humano é dotado de razão (Vernunft), uma faculdade secundária, mas que exerce função de pronunciada importância. A faculdade de razão, ao possibilitar a abstração, o raciocínio, e o alargamento da dimensão temporal, permite, também, que o indivíduo, a partir da reflexão e da experiência, encontre meios mais adequados para alcançar os seus fins. Isso não se dá pela alteração do caráter desse indivíduo, mas pelo refinamento de sua constelação de motivos, que significa a correção e o clareamento do conhecimento - o qual é o meio dos motivos. A educação, entendida pelo filósofo da vontade como um prêmio, atua nos indivíduos pela correção do conhecimento, através do ensino e do exemplo. Assim, a função pedagógica do educar tem como objetivo influenciar o indivíduo a agir dentro dos limites da lei e a optar pelos melhores meios para alcançar os seus fins - promovendo a melhoria civil e legal -, sem, com isso, prescrever ou moralizar.

Contudo, apesar de Schopenhauer negar repetidas vezes que o Estado tenha alguma função moralizante, deve-se lembrar que os indivíduos possuem um caráter adquirido que se “dá em seu uso no mundo (Weltgebrauch)" (cf. Schopenhauer, 2005, p. 391; Schopenhauer, 1911-1942, p. 357), e essas relações no mundo estão, em sua maior parte, pautadas sobre uma ótica econômico-jurídica regulada pelos Estados existentes. Dessa forma, em última instância, as relações dos indivíduos com o mundo

7 Propomos aqui o reconhecimento de uma sétima rubrica de injustiça, a saber, os crimes ambientais. 8 " $O$ código penal é um registro o mais completo possível de contramotivos opostos a todas as ações criminais presumíveis - tudo isso in abstracto, para fazer aplicação in concreto quando o caso ocorrer" (Schopenhauer, 2005, p. 441; Schopenhauer, 1911-1942, p. 407). 
são reguladas pelo Estado. Este, assim, agiria na formação do caráter adquirido dos indivíduos, atuando no refinamento da constelação de motivos desses, tornando-os, assim, menos toscos.

0 refinamento da constelação de motivos dos indivíduos poderia ter como norte mostrar a eles que possuir um meio ambiente preservado pode ser muito mais vantajoso para a manutenção da própria vida do que os ganhos econômicos em explorá-lo de forma não sustentável. Essa motivação tende a ganhar força e se tornar mais persuasiva tanto mais a situação ambiental caminhe para o limite do catastrófico.

Aqui, começamos a adentrar a perspectiva das motivações que fazem com que os indivíduos ajam. 0 movimento descrito acima seria uma espécie de novo esclarecimento do egoísmo: uma nova situação limite - que no momento é hipotética, podendo vir a se tornar real - que faz com que os indivíduos percebam que é preferível preservar o meio ambiente e arcar com o ônus e consequências envolvidas nesse ato de preservação, a arcar com as consequências dos perigos por de concorrer por recursos naturais em uma situação de precariedade, e, até mesmo, da própria ameaça de extinção. É como se o indivíduo notasse que, da mesma forma que renunciar à prática de injustiça é vantajoso, porque assim ele também não sofre injustiça, abdicar da exploração insustentável do meio ambiente - embora essa exploração the traga inúmeras vantagens - pode garantir a sua sobrevivência.

No âmbito do egoísmo, todo o cálculo de utilidade é baseado nas vantagens e desvantagens que o próprio indivíduo pode obter. É possível pensar em uma perspectiva um pouco diversa se a compaixão fosse a motivação para a ação do indivíduo. Nesse caso, se fosse possível constituir uma sociedade de indivíduos éticos, a preservação do meio ambiente poderia estar ligada, também, à proteção dos animais não-humanos e das futuras gerações, não apenas aos animais humanos.

\section{Considerações Finais}

A filosofia de Schopenhauer, apesar de não tratar de forma direta da questão dos Direitos Humanos de terceira geração - e ela nem poderia -, fornece elementos e ferramentas importantes para se pensar a questão. A partir de uma perspectiva teórica, é possível criar hipóteses sobre como as motivações agiriam na constituição de uma cultura do aparente respeito, do incentivo e da implementação dos direitos humanos que partisse dos indivíduos - seja essa cultura auto interessada ou desinteressada, i.e., guiada pelo egoísmo, ou pela compaixão, e, neste último caso, ela seria moralmente boa.

A partir de uma perspectiva prática, baseada nas finalidades e funções do Estado, é possível admitir ações pautadas na promoção da preservação do meio 
ambiente baseadas em ações institucionais fomentadas e implementadas pelo aparato do Estado, visando a proteção de seus membros. Esse atua no combate às injustiças, que ganha agora um novo registro, a saber, os "crimes ambientais", e na constelação de motivos dos seus cidadãos, mas, contudo, ele não alteraria - nem poderia - o que cada indivíduo é e quer, mostrando apenas um melhor meio para que cada um alcance seus fins. O Estado atuaria indiretamente, dessa forma, no fomento ao egoísmo esclarecido, promovendo, assim, uma espécie de pedagogia do egoísmo.

A questão que nos resta, mas que, infelizmente, não é possível responder, seria: “Nosso egoísmo perceberá em tempo hábil de evitar uma situação de catástrofe ambiental, que o melhor a fazer é preservar o meio ambiente?".

\section{Referências}

Bobbio, N. (1995). L'età dei diritti. Torino: Giulio Einaudi.

Bologna, M.; Aquino, G. (2020). Deforestation and world population sustainability: a quantitative analysis. Sci Rep 10, 7631. DOI: https://doi.org/10.1038/s41598-020-63657-6. Acesso em 15/08/2020.

Bonavides, P. (2006). Curso de direito constitucional. $19^{a}$ edição. São Paulo, SP: Malheiros.

Comparato, F. (2015). A Afirmação Histórica dos Direitos Humanos. 10ª edição. São Paulo, SP: Saraiva.

Durante, F. (2017). Direito natural e direitos fundamentais: a atualidade de Schopenhauer para o debate acerca dos direitos humanos. Tese de doutorado. Campinas, SP. Recuperado de: http://www.repositorio.unicamp.br/handle/REPOSIP/330589. Acesso em: 17/11/2020.

Global Footprint Network (s.d.). Annual Reports. Recuperado de http://www.footprintnetwork.org/en/index.php/GFN/page/annual_report. Acesso em 23/09/2016.

Marchi, W. (2010). Uma Reflexão sobre a Classificação dos Direitos Fundamentais. Revista lus et lustitia Eletrônica, 3(1), 36-44. Recuperado de: http://revistaunar.com. $\mathrm{br} /$ juridica/documentos/vol3_n1_2010/UMAREFLEXAOSOBREACLASSIFICACAODOSDIREITOSFUNDAMENTIAS. pdf. Acesso em: 23/09/2016.

Maranhão, N. (2011). A afirmação histórica dos direitos fundamentais. A questão das dimensões ou gerações de direitos. E-Gov UFSC: Portal de e-governo, inclusão digital e sociedade do conhecimento. Recuperado de: http://www.egov. ufsc.br/portal/conteudo/afirma\%C3\%A7\%C3\%A3o-hist\%C3\%B3rica-dos-direitos-fundamentais. Acesso em 23/09/2016.

Schopenhauer, A. (1911-1942). Arthur Schopenhauers sämtliche Werke. Hrsg. Von Paul Deussen. Munique: R. Piper.

Schopenhauer, A. (1911-1942). Arthur Schopenhauers handschriftlicher Nachlaß. Philosophische Vorlesungen - Metaphysik der Sitten. In: Arthur Schopenhauers sämtliche Werke, vol. X. Hrsg. Von Paul Deussen. Munique: R. Piper, pp.367-584.

Schopenhauer, A. (1911-1942). Über die Grundlage der Moral. In: Arthur Schopenhauers sämtliche Werke, vol. III. Hrsg. Von Paul Deussen. Munique: R. Piper, pp.573-746. 
Schopenhauer, A. (2001). Sobre o fundamento da moral. Tradução de Maria Lucia Mello Oliveira Cacciola. São Paulo: Martins Fontes.

Schopenhauer, A. (2005). O Mundo como Vontade e como Representação, $1^{\circ}$ Tomo. Tradução, apresentação, notas e índices de Jair Barboza. São Paulo, SP: Editora UNESP.

WWF. (2014). Living Planet Report 2014. Species and spaces, people and places. Gland: WWF International. Recuperado de: http://assets.worldwildlife.org/publications/723/files/ original/WWF-LPR2014-low_res.pdf?1413912230\&_ga=1.171834528.1276102506.1476325280. Acesso em $15 / 08 / 2020$.

WWF. (2018). Living Planet Report 2018. Aiming higher. Gland: WWF International. Recuperado de: https://www.wwf.org.uk/sites/default/files/2018-10/LPR2018_Full\%20Report.pdf. Acesso em 17/11/2020.

Recebido em: 15.08.2020

Aceito em: 16.10 .2020

Esta obra está licenciada com uma Licença Creative Commons Atribuição-NãoComercial- 